\title{
Fever of unknown origin (FUO): which are the factors influencing the final diagnosis? A 2005-2015 systematic review
}

\author{
Francesco Maria Fusco ${ }^{1 *} \mathbb{D}$, Raffaella Pisapia ${ }^{2}$, Salvatore Nardiello ${ }^{3}$, Stefano Domenico Cicala ${ }^{4}$, \\ Giovanni Battista Gaeta ${ }^{5}$ and Giuseppina Brancaccio ${ }^{6}$
}

\begin{abstract}
Background: The differential diagnosis of Fever of Unknown Origin (FUO) is very extensive, and includes infectious diseases (ID), neoplasms and noninfectious inflammatory diseases (NIID). Many FUO remain undiagnosed. Factors influencing the final diagnosis of FUO are unclear.

Methods: To identify factors associated with FUO diagnostic categories, we performed a systematic review of classical FUO case-series published in 2005-2015 and including patients from 2000. Moreover, to explore changing over time, we compared these case-series with those published in 1995-2004.

Results: Eighteen case-series, including 3164 patients, were included. ID were diagnosed in $37.8 \%$ of patients, NIID in $20.9 \%$, and neoplasm in $11.6 \%$, FUO were undiagnosed in 23.2\%. NIIDs significantly increased over time. An association exists between study country income level and ID (increasing when the income decreases) and undiagnosed FUO (increasing when the income increases); even if not significant, the use of a pre-defined Minimal Diagnostic Work-up to qualify a fever as FUO seems to correlate with a lower prevalence of infections and a higher prevalence of undiagnosed FUO. The multivariate regression analysis shows significant association between geographic area, with ID being more frequent in Asia and Europe having the higher prevalence of undiagnosed FUO. Significant associations were found with model of study and FUO defining criteria, also.

Conclusions: Despite advances in diagnostics, FUO still remains a challenge, with ID still representing the first cause. The main factors influencing the diagnostic categories are the income and the geographic position of the study country.
\end{abstract}

Keywords: Fever of unknown origin, Diagnostic outcomes, Infectious diseases, Neoplasms, Noninfectious inflammatory diseases

\section{Background}

Fever of unknown origin (FUO) was originally defined by Petersdorf and Beeson [1] as an illness of more than 3 weeks' duration, with fever greater than $38.3^{\circ} \mathrm{C}$ $\left(101^{\circ} \mathrm{F}\right)$ on several occasions, the cause of which is uncertain after 1 week of in-hospital investigations. To meet the evolution of diagnostic capabilities, some modifications in the definition of FUO occurred through the years: in 1991, Durak and Street proposed

\footnotetext{
* Correspondence: francescomaria.fusco@uslcentro.toscana.it ${ }^{1}$ Infectious Diseases Unit 1, S. Maria Annunziata Hospital, Central Tuscany Health Unit, Via dell'Antella 54, 50012 Bagno a Ripoli, FI, Italy

Full list of author information is available at the end of the article
}

that there be a distinction between classical FUO and three other types, namely nosocomial, neutropenic and HIV-associated FUO; moreover, they reduced the duration of investigation, before defining a FUO, to at least 3 days in hospital or at least 3 outpatient visits [2]. In recent years, some authors [3-6] proposed to change the quantitative criterion (diagnosis uncertain after 1 week or 3 days of investigation) with the qualitative requirement that fever remained undiagnosed after a minimal diagnostic work-up had been performed; however, investigations that should be included in the work-up remain a matter of debate.

C The Author(s). 2019 Open Access This article is distributed under the terms of the Creative Commons Attribution 4.0 International License (http://creativecommons.org/licenses/by/4.0/), which permits unrestricted use, distribution, and 
The differential diagnosis of FUO is the most wide-ranging in medicine, since more than 200 conditions have been identified as the cause of FUO [7]. Infectious diseases (ID), neoplasms and non-infectious inflammatory diseases (NIID) are the main categories of diseases causing FUO. However, despite recent advances in medicine, about a quarter of FUO remains undiagnosed [7, 8].

In published case-series, the spectrum of diseases causing FUO is very different, due to several factors still poorly explored. Among these factors, geographic prevalence patterns, the patient's age, and the gap between the investigative resources of developing and developed countries may have a great significance. Clinical profile of FUO could have changed over time, in consideration of advances in diagnostic techniques, evolving socioeconomic status of the countries, development of new broad-spectrum pharmaceuticals, the emergence of new diseases and the attitude of physicians. The different methodologies among caseseries (definition of FUO, retrospective or prospective model, use and composition of a minimal diagnostic work-up), may contribute to determine the final distribution of various causes of fever and the prevalence of FUO remaining without a diagnosis.

In order to identify the main factors influencing the clinical spectrum of FUO, we performed a systematic review of classical FUO case series including patients from 2000 and published in 2005-2015. Moreover, to describe the FUO characteristics over time, we compared our results with those of a systematic review on the same topic previously performed by our group, that analysed case-series published from 1994 to 2004 including patients from 1972 to 2002 [8].

\section{Methods}

This paper has been written according to PRISMA checklist for the reporting of systematic reviews and meta-analysis [9]. We performed a systematic review with the following inclusion criteria: all case-series about classical FUO, published in 2005-2015, and having a starting data of patients' inclusion from 2000 onwards.

\section{Search strategy}

Eligible studies for this systematic review were identified through searches of PubMed for articles published from January 2005, to May 2015, by use of the following terms "fever of unknown origin" or "FUO" or "Pyrexia of unknown origin" or "PUO", both as MeSH and Search terms. Articles resulting from these searches and relevant eligible studies cited in those articles were reviewed. Articles published in English were included.

\section{Data selection}

The analysis of results emerged from this search strategy was conducted independently by two researchers (FMF, RP), on the basis of the title, abstract and full text were appropriate. After the selection of eligible studies, data from selected case-series were extracted manually by 3 researchers, independently. Later in the data analysis, all authors analysed extracted data to clarify some slight differences emerged in the data extraction. We analysed data about patients' characteristics ( $\mathrm{M} / \mathrm{F}$ ratio, mean age), the model of study, the criteria used for defining FUO, the geographic area and the study country income classification, the use of a minimal diagnostic work-up, and the final diagnosis.

The quality of selected study was assessed according to tool proposed by Mudar at al [10], limited to questions $1,2,3,7$ and 8 , since questions $4-6$ are relevant to cases of adverse drug events.

\section{Statistical methodology}

Statistical differences among frequencies were calculated with the Mantel-Haenszel Chi-squared test, using an alpha significance level of 0.05 . In order to identify the factors influencing the clinical spectrum of FUO, a logistic regression was performed using each final diagnostic category as outcome variable and significant variables at univariate analysis as covariate. The results derived from the logistic regression were represented by a forest plot, in order to graphically show the odds estimates with the relative confidence intervals, highlighting the type of association between the variables and outcomes. Data were analysed using the SAS software, version 9.3.

\section{Results}

\section{Results of data selection}

The search approach produced 1682 results. Among these, 1309 were excluded based on the title or abstract: 889 were not pertinent, 55 were about HIV patients, 80 described FUO in neutropenic patients, 225 among paediatric populations, finally in 60 cases the title was not clear and the abstract not available. The remaining 373 papers have been read as full text, and 341 have been excluded: 184 were single case reports, 79 were case series investigating the diagnostic value of a single procedure, 27 were papers describing the incidence of a single disease among a case-series, 51 were comments or reviews without original data. Among the remaining 32 case-series, 13 have been excluded because the study period started before 2000, and 2 because they included geriatric patients only. An additional case-series has been retrieved among the bibliography of selected papers, therefore we finally included 18 case series [3, 11-27]. Figure 1 shows the complete flow chart for study selection. 


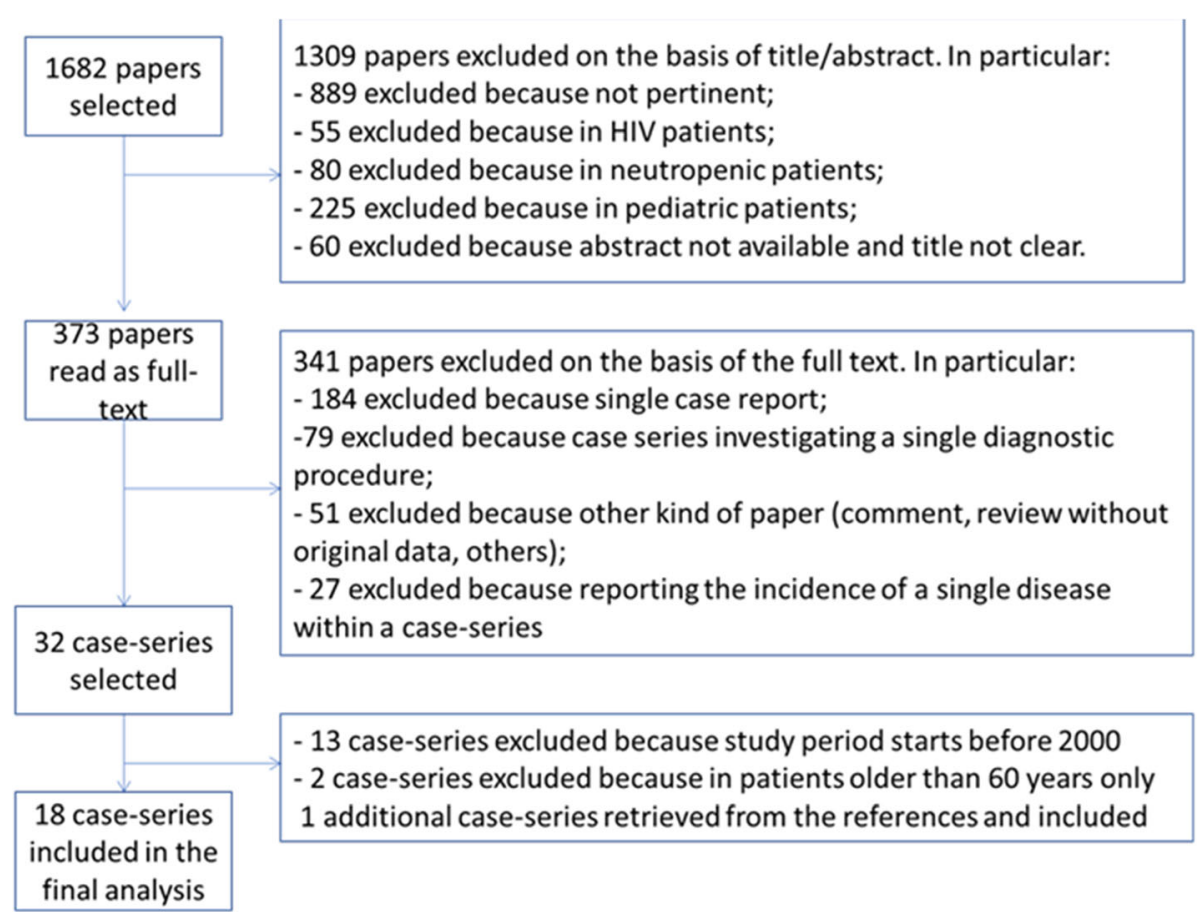

Fig. 1 Flow Chart for the selection of 2006-2014 case-series about FUO

\section{Characteristics of selected studies}

A total of 18 case-series, including 3164 patients, were analysed. General characteristics of case-series and patients included are summarized in Table 1. Quality of studies resulted good, with scores ranging from 3 to 5 (range 0-5). Case-series were from Asia or Europe; Middle East was the most represented among WHO regions. No case-series from Africa and from the Americas matched inclusion criteria. According to the World Bank income classification [28], 8 case-series were from upper-medium income, 6 from high income areas, and the remaining 4 are from lower-medium income areas. Most studies were retrospective, and most of them defined FUO according to Durak and Street definition; in 5 studies the criteria for defining FUO were personal, mostly including a qualitative assessment after a minimal diagnostic work-up, rather than a quantitative, time-dependent definition only. The enrolment period ranged from 1 to 10 years. Each case-series included at least 52 patients (range 52-997), 49.6\% of patients were male, aged from 10 to 94 years.

Comparing these case-series (new case-series) with our previous systematic review, including 11 case series (old case-series) published in 1995-2004, no differences were present in geographical distribution, with most of case-series performed in Asia in both cases. Differences were present regarding the gender distribution (males $56 \%$ in old case-series and $49.6 \%$ in new case-series, $p=0,003)$ and the mean age of patients (40.6 in old case-series to 45.8 in new ones).
Most studies were retrospective in both series. On the contrary, the definition criteria of FUO by Durak and Street was more frequently adopted among new case-series (11 out of 18) compared with old caseseries (3 out of 11).

\section{Use of a minimal diagnostic work-up to qualify a fever as FUO}

A predefined minimal diagnostic work-up to qualify a fever as FUO was adopted in 6 series and described in detail in 4. In general, complete blood count, routine haematochemical tests, inflammatory indexes, including $\mathrm{C}$-reactive protein and/or Erythrocyte Sedimentation Rate, urine analysis, blood and urine cultures, chest x-ray and abdominal and pelvic ultrasonography were included. Four case-series performing the minimal diagnostic work-up were from high-income countries and two, in which it was reported but not described, were from an upper-medium income country. The routine use of a minimal diagnostic work-up decreased from $55 \%$ in old case-series (6 out of 11 ) to $33 \%$ in new case-series (6 out of 18). A comparison between the tests and procedures included in the new and old caseseries is reported in Fig. 2. Instrumental diagnostic procedures, such as TC scan and ultra-sonography, were more frequently performed in the new case-series, as immunological tests and screening tests for tuberculosis. Instrumental procedures were more frequently included in the minimal diagnostic work-up in studies coming from high-income countries; as expected, some specific tests for 
Table 1 General characteristics of the selected case-series

\begin{tabular}{|c|c|c|c|c|c|c|c|c|c|c|c|c|c|}
\hline Ref & First Author & Year & $\begin{array}{l}\text { Quality } \\
\text { assessment } \\
\text { (range 0-5) }\end{array}$ & Country & $\begin{array}{l}\text { Geographical } \\
\text { area }\end{array}$ & $\begin{array}{l}\text { Country } \\
\text { income } \\
\text { classification }\end{array}$ & $\begin{array}{l}\text { Model } \\
\text { of } \\
\text { study }^{\text {a }}\end{array}$ & $\begin{array}{l}\text { FUO } \\
\text { criteria } \\
\text { b }\end{array}$ & $\begin{array}{l}\text { Study } \\
\text { period }\end{array}$ & $\begin{array}{l}\text { Number } \\
\text { of } \\
\text { patients }\end{array}$ & $\begin{array}{l}M / F \\
\text { ratio }\end{array}$ & $\begin{array}{l}\text { Mean } \\
\text { age } \\
\text { (range) }\end{array}$ & $\begin{array}{l}\text { Minimal } \\
\text { diagnostic } \\
\text { work-up }\end{array}$ \\
\hline [11] & Yu & 2014 & 3 & China & Far East & $\begin{array}{l}\text { Upper- } \\
\text { medium }\end{array}$ & 1 & 1 & $\begin{array}{l}2010- \\
2011\end{array}$ & 107 & $\begin{array}{l}54 / \\
53\end{array}$ & $\begin{array}{l}48 \\
(15- \\
94)\end{array}$ & $\mathrm{No}$ \\
\hline [12] & Mir & 2014 & 5 & India & Southern Asia & $\begin{array}{l}\text { Lower- } \\
\text { medium }\end{array}$ & 2 & 1 & $\begin{array}{l}2010- \\
2012\end{array}$ & 91 & $\begin{array}{l}621 \\
29\end{array}$ & $\begin{array}{l}\text { NA } \\
(16- \\
80)\end{array}$ & No \\
\hline [13] & Naito & 2013 & 4 & Japan & Far East & High & 1 & 1 & 2011 & 121 & $\begin{array}{l}69 / \\
52\end{array}$ & $\begin{array}{l}59 \\
(19- \\
94)\end{array}$ & No \\
\hline [14] & Robine & 2014 & 5 & France & Europe & High & 1 & 1 & $\begin{array}{l}2002- \\
2012\end{array}$ & 103 & $\begin{array}{l}54 / \\
49\end{array}$ & $\begin{array}{l}57 \\
(19- \\
84)\end{array}$ & Yes \\
\hline [15] & Vanderschueren & 2014 & 5 & Belgium & Europe & High & 1 & 3 & $\begin{array}{l}2000- \\
2010\end{array}$ & 436 & NA & $\begin{array}{l}50 \\
(\mathrm{NA})\end{array}$ & Yes \\
\hline [16] & Alavi & 2013 & 3 & Iran & Middle East & $\begin{array}{l}\text { Upper } \\
\text {-medium }\end{array}$ & 1 & 3 & $\begin{array}{l}2007- \\
2011\end{array}$ & 106 & $\begin{array}{l}57 / \\
49\end{array}$ & $\begin{array}{l}50 \\
(18- \\
76)\end{array}$ & NA \\
\hline [17] & Mahmood & 2013 & 3 & Pakistan & Southern Asia & $\begin{array}{l}\text { Lower- } \\
\text { medium }\end{array}$ & 1 & 1 & $\begin{array}{l}2006- \\
2011\end{array}$ & 205 & $\begin{array}{l}111 / \\
94\end{array}$ & $\begin{array}{l}38 \\
\text { (NA) }\end{array}$ & No \\
\hline [18] & Shi & 2013 & 5 & China & Far East & $\begin{array}{l}\text { Upper } \\
\text {-medium }\end{array}$ & 1 & 2 & $\begin{array}{l}2004- \\
2010\end{array}$ & 997 & $\begin{array}{l}466 / \\
531\end{array}$ & $\begin{array}{l}43 \\
(14- \\
85)\end{array}$ & No \\
\hline [19] & Mete & 2012 & 3 & Turkey & Middle East & $\begin{array}{l}\text { Upper } \\
\text {-medium }\end{array}$ & 1 & 1 & $\begin{array}{l}2001- \\
2009\end{array}$ & 100 & $\begin{array}{l}53 / \\
47\end{array}$ & $\begin{array}{l}45 \\
(16- \\
82)\end{array}$ & Yes $^{c}$ \\
\hline [20] & Pedersen & 2012 & 4 & Denmark & Europe & High & 1 & 1 & $\begin{array}{l}2005- \\
2010\end{array}$ & 52 & $\begin{array}{l}36 / \\
16\end{array}$ & $\begin{array}{l}48 \\
(34- \\
64)\end{array}$ & No \\
\hline [21] & Ali-Eldin & 2011 & 3 & Egypt & Middle East & $\begin{array}{l}\text { Lower- } \\
\text { medium }\end{array}$ & 2 & 3 & $\begin{array}{l}2009- \\
2010\end{array}$ & 93 & $\begin{array}{l}45 / \\
48\end{array}$ & $\begin{array}{l}34 \\
\text { (NA) }\end{array}$ & No \\
\hline [22] & Bandyopadhyay & 2011 & 4 & India & Southern Asia & $\begin{array}{l}\text { Lower- } \\
\text { medium }\end{array}$ & 2 & 1 & $\begin{array}{l}2008- \\
2009\end{array}$ & 164 & $\begin{array}{l}82 / \\
82\end{array}$ & $\begin{array}{l}42 \\
\text { (NA) }\end{array}$ & No \\
\hline [23] & Adil Khalil & 2010 & 4 & Iraq & Middle East & $\begin{array}{l}\text { Upper } \\
\text {-medium }\end{array}$ & 2 & 1 & $\begin{array}{l}2002- \\
2009\end{array}$ & 55 & $\begin{array}{l}27 / \\
28\end{array}$ & $\begin{array}{l}43 \\
(10- \\
76)\end{array}$ & No \\
\hline [24] & $\mathrm{Hu}$ & 2008 & 3 & China & Far East & $\begin{array}{l}\text { Upper } \\
\text {-medium }\end{array}$ & NA & 2 & $\begin{array}{l}2002- \\
2003\end{array}$ & 142 & $\begin{array}{l}69 / \\
73\end{array}$ & $\begin{array}{l}49 \\
(14- \\
81)\end{array}$ & Yes $^{c}$ \\
\hline [25] & Kucukardali & 2007 & 4 & Turkey & Middle East & $\begin{array}{l}\text { Upper } \\
\text {-medium }\end{array}$ & 2 & 1 & $\begin{array}{l}2003- \\
2004\end{array}$ & 154 & $\begin{array}{l}83 / \\
71\end{array}$ & $\begin{array}{l}42 \\
(17- \\
75)\end{array}$ & No \\
\hline [3] & Bleeker-Rovers & 2007 & 5 & Netherland & Europe & High & 2 & 3 & $\begin{array}{l}2003- \\
2005\end{array}$ & 73 & $\begin{array}{l}33 / \\
40\end{array}$ & $\begin{array}{l}54 \\
(26- \\
87)\end{array}$ & Yes \\
\hline [26] & Colpan & 2007 & 4 & Turkey & Middle East & $\begin{array}{l}\text { Upper } \\
\text {-medium }\end{array}$ & NA & 3 & $\begin{array}{l}2001- \\
2004\end{array}$ & 71 & $\begin{array}{l}40 / \\
31\end{array}$ & $\begin{array}{l}42 \\
(16- \\
80)\end{array}$ & No \\
\hline [27] & Chin & 2006 & 5 & Taiwan & Far East & High & 2 & 1 & $\begin{array}{l}2001- \\
2002\end{array}$ & 94 & $\begin{array}{l}57 / \\
37\end{array}$ & $\begin{array}{l}56 \\
(18- \\
86)\end{array}$ & Yes \\
\hline
\end{tabular}

${ }^{a}$ Model of Study: 1, Retrospective; 2, Prospective; ${ }^{b}$ FUO criteria: 1, Durak and Street; 2, Petersdorf and Beeson; 3, personal criteria; ${ }^{\mathrm{c}}$ Diagnostic work-up performed, but not detailed; NA Not Available

tropical diseases (such as malaria and typhoid fever tests) were included in studies coming from medium-lower income countries.
Diagnostic outcomes

Final diagnoses in the 18 case-series are reported in Table 2. Overall, infections were the most represented 


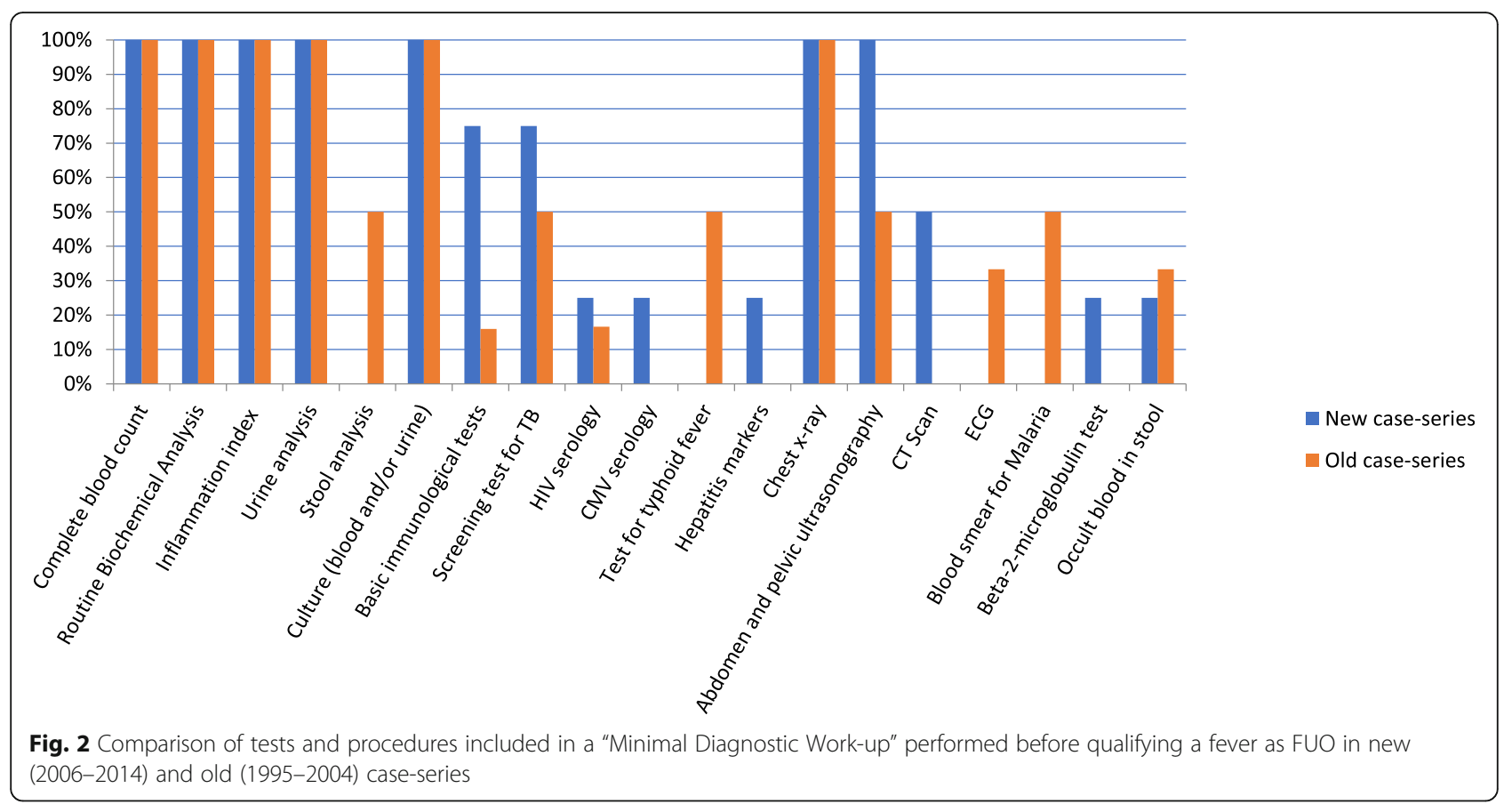

diagnosis (37,8\%), followed by NIID (20,9\%), neoplasm $(11,6 \%)$, other diseases $(6,5 \%)$; the diagnosis remained unknown in $23,2 \%$ of cases.

Table 3 shows the 10 most frequent diagnoses for infectious diseases, neoplasm and NIID. Among infectious diseases, mycobacterial infections (mainly extra-pulmonary tuberculosis) were predominant, followed by endocarditis and abscesses; haematological malignancies represented $58 \%$ of neoplasm; diagnoses among NIID were more heterogeneous, with Adult Onset Still's

Table 2 Diagnostic categories in 18 case-series 2006-2014

\begin{tabular}{|c|c|c|c|c|c|c|c|c|}
\hline Ref & First Author & Year & Number of patients & Infectious Diseases (\%) & Neoplasm (\%) & NIID (\%) & Other (\%) & No diagnosis (\%) \\
\hline$[11]$ & $\mathrm{Yu}$ & 2014 & 107 & 29.9 & 17.8 & 16.8 & 14.0 & 21.5 \\
\hline [12] & Mir & 2014 & 91 & 44.0 & 12.0 & 12.0 & 5.0 & 27.0 \\
\hline [13] & Naito & 2013 & 121 & 23.1 & 10.7 & 30.6 & 12.4 & 23.1 \\
\hline [14] & Robine & 2014 & 103 & 23.5 & 2.9 & 30.1 & 4.9 & 50.5 \\
\hline [15] & Vanderschueren & 2014 & 436 & 17.0 & 11.0 & 24.0 & 9.9 & 39.0 \\
\hline [16] & Alavi & 2013 & 106 & 44.3 & 12.3 & 17.9 & 10.4 & 15.0 \\
\hline [17] & Mahmood & 2013 & 205 & 48.8 & 12.7 & 18.6 & 3.4 & 16.6 \\
\hline [18] & Shi & 2013 & 997 & 48.0 & 7.9 & 16.9 & 7.1 & 16.6 \\
\hline [19] & Mete & 2012 & 100 & 26.0 & 14.0 & 38.0 & 2.0 & 20.0 \\
\hline [20] & Pedersen & 2012 & 52 & 32.0 & 13.0 & 55.0 & 0.0 & 21.0 \\
\hline [21] & Ali-Eldin & 2011 & 93 & 41.9 & 30.1 & 15.0 & 0.0 & 12.9 \\
\hline [22] & Bandyopadhyay & 2011 & 164 & 54.9 & 22.0 & 11.0 & 0.0 & 12.2 \\
\hline [23] & Rami & 2010 & 55 & 32.7 & 16.4 & 25.4 & 5.4 & 20.0 \\
\hline [24] & $\mathrm{Hu}$ & 2008 & 142 & 35.9 & 12.7 & 32.4 & 4.9 & 14.9 \\
\hline [25] & Kucukardali & 2007 & 154 & 34.4 & 14.3 & 30.5 & 5.2 & 15.6 \\
\hline [3] & Bleeker-Rovers & 2007 & 73 & 16.0 & 7.0 & 22.0 & 4.0 & 51.0 \\
\hline$[26]$ & Colpan & 2007 & 71 & 45.1 & 14.1 & 26.8 & 5.6 & 8.5 \\
\hline \multirow[t]{2}{*}{ [27] } & Chin & 2006 & 94 & 57.4 & 8.5 & 7.4 & 8.5 & 18.1 \\
\hline & Total & & 3164 & 37.8 & 11.6 & 20.9 & 6.5 & 23.2 \\
\hline
\end{tabular}


Disease, Systemic Lupus Erythematosus and vasculitis representing the most frequent.

When compared with old case series, no differences emerged in the frequencies of infectious diseases and neoplasm, while NIIDs were significantly increased in the present analysis (Table 4). The percentage of FUO remaining without diagnosis tended to decrease in more recent case-series.

\section{Factors influencing the distribution of final diagnosis}

We investigated the association of different factors (geographic area, income of the country where the study was performed, model of study, FUO definition criteria, and routine adoption of a Minimal Diagnostic Work-up) with the diagnostic outcome (Fig. 3 a-e).

At multivariable analysis (Fig. 4 a-d), all diagnostic outcomes were influenced by the geographical area where the study was performed: in particular, the risk of having an infection was more than 4 times higher in Southern Asia (OR 4.6; C.I. 1,89-11,91) and 3 times higher in Far East Asia (OR 3.0; C.I. 1, 67-5,62) than in Europe; the diagnosis of NIID was more frequent in Middle East and Far East Asia than Southern Asia, the risk of having a NIID in Europe

Table 310 most frequent diagnosis for infectious diseases, neoplasm and NIID in 18 case-series 2006-2014

\begin{tabular}{|c|c|c|}
\hline Diagnosis & $\mathrm{N}^{\circ}(\%)$ & $\mathrm{N}^{\circ}$ of case-series including the diagnosis \\
\hline \multicolumn{3}{|c|}{ Infectious Diseases (out of 1197 cases from 18 case-series where details are available) } \\
\hline Mycobacterial diseases & $440(36.8 \%)$ & 17 \\
\hline Endocarditis & 119 (9.9\%) & 15 \\
\hline Brucellosis & $58(4.8 \%)$ & 9 \\
\hline Internal abscesses & $49(4.1 \%)$ & 11 \\
\hline Salmonellosis & $43(3.6 \%)$ & 9 \\
\hline CMV infections & $43(3.6 \%)$ & 7 \\
\hline Urinary tract infections & $40(3.3 \%)$ & 11 \\
\hline Sepsis & $20(1.7 \%)$ & 4 \\
\hline HIV/AIDS & $20(1.7 \%)$ & 4 \\
\hline Osteoarticular infections & $18(1.5 \%)$ & 5 \\
\hline \multicolumn{3}{|c|}{ Neoplasms (out of 289 cases from 15 case-series where details are available) } \\
\hline Lynphomas (including Hodgkin, Non-Hodgkin, not specified) & $169(58.5 \%)$ & 9 \\
\hline Solid tumors (not specified) & $25(8.7 \%)$ & 4 \\
\hline Leukemias & $17(5.9 \%)$ & 7 \\
\hline Other cancers (not specified) & $14(4.8 \%)$ & 5 \\
\hline Myelodysplastic syndrome & $11(3.8 \%)$ & 7 \\
\hline Colon cancers & $10(3.5 \%)$ & 5 \\
\hline Multiple mieloma & $8(2.8 \%)$ & 6 \\
\hline Gastric cancers & $5(1.7 \%)$ & 3 \\
\hline Mesotheliomas & $5(1.7 \%)$ & 3 \\
\hline Castleman's diseases & $4(1.4 \%)$ & 3 \\
\hline \multicolumn{3}{|l|}{ NIIDs (out of 642 cases from 17 case-series where details are available) } \\
\hline Adult-onset Still's disease & $177(27.6 \%)$ & 15 \\
\hline Systemic Lupus Erythematosus & $71(11.1 \%)$ & 14 \\
\hline Vasculitis & $63(9.8 \%)$ & 8 \\
\hline Rheumatic Polymyalgia & $44(6.9 \%)$ & 8 \\
\hline Giant Cells Arteritis & $32(5.0 \%)$ & 6 \\
\hline Mixed connective diseases (not specified) & $31(4.8 \%)$ & 5 \\
\hline Sarcoidosis & $21(3.3 \%$ & 7 \\
\hline Rheumatoid Arthritis & $17(2.6 \%)$ & 6 \\
\hline Wegener Granulomatosis & $14(2.2 \%)$ & 4 \\
\hline Polyarteritis nodosa & $13(2.0 \%)$ & 5 \\
\hline
\end{tabular}


Table 4 Comparison of main diagnostic categories among FUO case-series in 2005-2015 and FUO case-series in 1995-2004

\begin{tabular}{llll}
\hline & $\begin{array}{l}\text { Old case-series } \\
(1995-2004)\end{array}$ & $\begin{array}{l}\text { New case-series } \\
(2006-2014)\end{array}$ & - \\
\hline$N^{\circ}$ of patients & 1488 & 3164 & - \\
Male (\%) & 56,2 & 49,6 & - \\
Mean age & 40,6 & $1197(38 \%)$ & 3,8 \\
Infectious Diseases & $545(37 \%)$ & $366(12 \%)$ & $\mathbf{0}$ \\
Neoplasm & $167(11 \%)$ & $661(21 \%)$ & $<, 731$ \\
NIID & $236(16 \%)$ & $206(7 \%)$ & $<0,001$ \\
Others & $155(10 \%)$ & $734(23 \%)$ & 0,051 \\
No diagnosis & $385(26 \%)$ &
\end{tabular}

Variables with significant statistical association $(p<0,05)$ are in bold

vs Southern Asia was close to significance (OR 4.17; IC 0.95-18.41); the diagnosis of neoplasm was more frequent in the case-series from Southern Asia and Middle East vs those from Far East Asia and Europe. The risk of having an undiagnosed FUO was higher in Europe vs all other geographical areas. The prospective model of the study was associated with a higher risk to have infections (OR 2,24; C.I. 1,43-3, 46); the frequency of neoplasm was lower if Durak and Street criteria were used, and that of NIID if personal criteria were used. Among other factors analysed, the routine use of a Minimal Diagnostic work-up is not significant in any diagnostic categories, even if the performance of the work-up is associated with a lower prevalence of infections and a higher prevalence of undiagnosed FUO. Similarly, the income level of the country is not statistically significant, but in general there is an association between study country income level and ID and neoplasms (increasing when the income decreases) and NIID and undiagnosed FUO (increasing when the income increases),

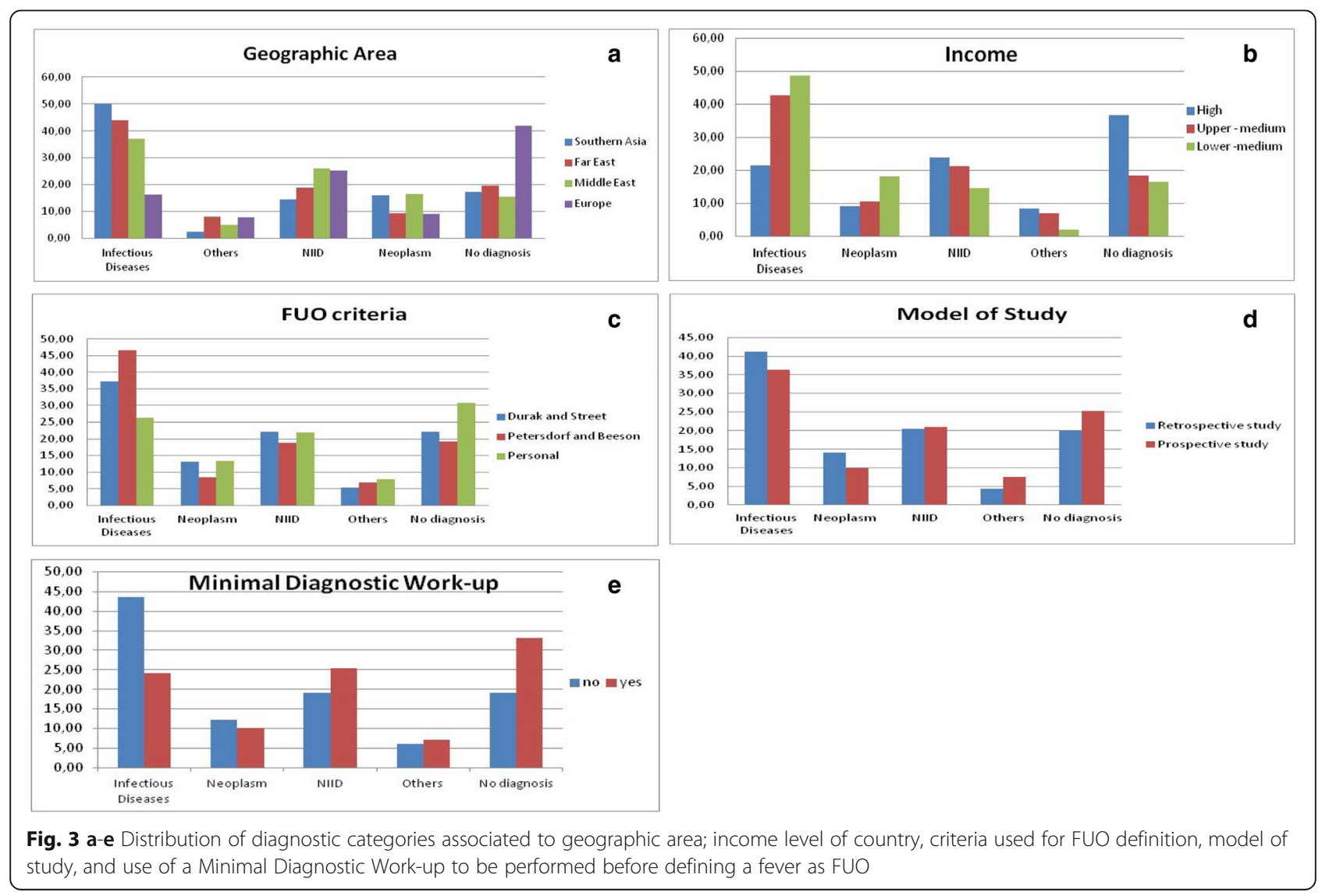



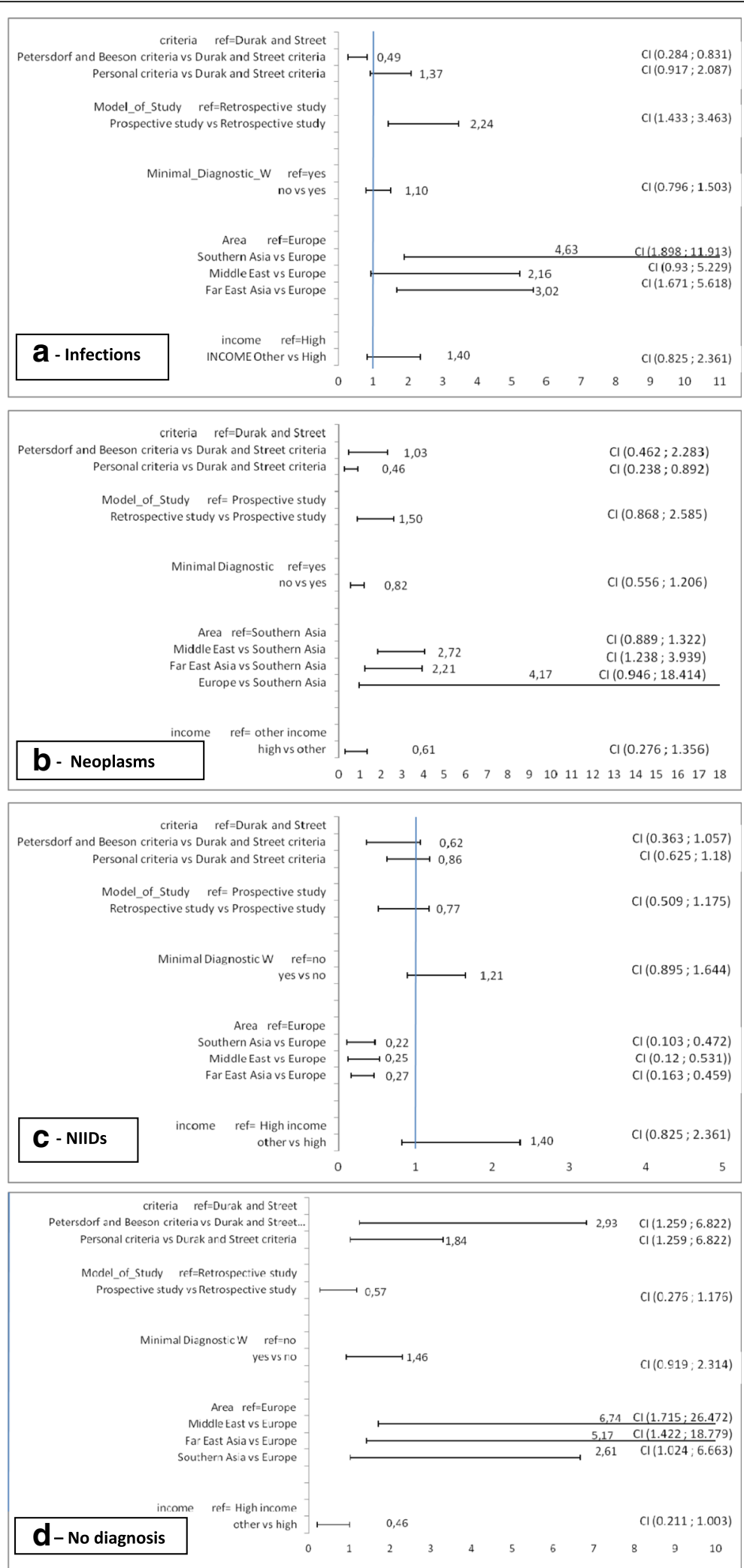

Fig. 4 a-d Multivariate logistic regression models for infection (a), neoplasm (b), NIID (c), undiagnosed FUO (d) 


\section{Discussion}

The general interest towards FUO seems to have increased over time: the present analysis covering a study period from 2005 to 2015, included 18 studies and 3164 patients, as compared to 11 papers published and 1488 patients retrieved in our previous analysis [8]. These differences could be due to a major number of patients with fever who can access medical investigation and care. In fact, especially in lower-medium and uppermedium income countries, the urbanization and the general increase of quality and duration of life may have led to the detection of some feverish patients who would not get medical attention in a rural, poorer environment. At the same time, the increased number of patients may be due to a renewed interest into FUO, mainly in Asian lower-medium and upper-medium income countries.

Surprisingly, no case-series were available from the Americas and from Africa. In African countries, it may be due to the vast prevalence of acute febrile illness overwhelming the health systems, while we have no reasonable explanations for the lack of studies from North, Central and South America.

\section{Main study finding}

Our approach based on income per region revealed a high heterogeneity in patient selection and particularly in diagnostic flowcharts. Infectious diseases remain the main cause of FUO. This is evident for lower-medium and upper-medium income countries, where infectious diseases represent 48 and $42 \%$ of the final diagnoses, respectively. Among infections, many "hard-to-diagnose" infectious diseases were included, such as mycobacterial diseases, endocarditis, internal abscesses, and osteoarticular infections. Possibly, recent advances in diagnostic imaging, such as the larger use of CT-scan, and in molecular biology laboratory methods contributed to these diagnoses.

NIIDs significantly increased over time, representing in new case-series $21 \%$ of final diagnoses. Advances in knowledge and clinicians' awareness for these pathologies increased in recent decades, and this probably led to their higher prevalence among FUO. Another factor potentially contributing is the increased use of basic immunological tests in the minimal diagnostic work-up among the new case-series, that may have contributed to identify potential diagnostic clues about NIID among FUO patients. On the contrary, despite advances in diagnostic imaging and the diffusion of these methodologies to upper-medium and lower-medium income countries too, the prevalence of neoplasm did not change over time, such as the prevalence of FUO that remained undiagnosed.

A minimal diagnostic work-up, to be performed before qualifying a fever as a FUO, is not widely adopted.
Considering the differences in diagnostic resources and capabilities in different geographic areas, the application of a merely quantitative criteria (3 days of in-hospital investigations or 3 outpatient visits) seems inadequate. Instead, the application of a minimal set of diagnostic procedures, including biochemistry, blood and urine cultures, basic imaging procedures and a set of infectious diseases screening tests determined on local epidemiological data, seems more reasonable, and has been advocated by some authors $[3-6,20,25]$. In this way, the patients classified as having FUO would be more easily comparable. However, despite these reasons, the use of a minimal diagnostic work-up is less frequent among new caseseries, and mostly limited to studies from Europe or other high-income countries.

Mostly all explored factors influenced the final diagnostic outcomes, according to logistic regression. The geographic area of the study strongly influenced the distribution of final diagnoses: infections, as expected, were more frequently present in Southern and Far-East Asia; NIIDs were less frequently diagnosed in Southern Asia (case-series from India and Pakistan), where the clinical awareness towards these diseases is supposed to be lower; instead, do not have a clear geographic distribution. Undiagnosed FUO are disproportionally present in Europe: among the 4 European case-series, a minimal diagnostic work-up was applied in 3, and this might have contributed to select more challenging FUO cases, a sort of "real FUO", consequently more difficult to be diagnosed. Of note, the use of diagnostic work-up, as "standing-alone factor", is not associated with a higher prevalence of undiagnosed FUO at logistic regression.

\section{Limitations of the study}

A possible limitation is represented by the great heterogeneity of the different studies, which may introduce some bias, using either multilevel or non-multilevel logistic regression analysis. Further studies on the same issue may overcome this limitation using Bayesian multilevel model that have shown potential to perform well with limited clusters in some scenarios [29, 30].

Another limitation might reside in the search criteria: we did not explore "grey literature", including abstracts, reports, congress communications. Moreover, we limited our research to English language papers, and this may have led to the exclusion of papers written in other largely diffused languages, such as French and, especially, Spanish (and this may be the reason for the lack of studies from Central and South America). Other intrinsic limitations were the retrospective design of most studies and the different criteria used for including 
patients (Petersdorf and Beeson criteria, Durak and Street criteria, and personal criteria in some cases), leading to a poor comparability.

\section{Conclusions}

Despite these limits, our study puts forward many interesting remarks. Even if infections represent the most frequent category among final diagnosis, our study confirms that the spectrum of FUO is huge, including many different diseases and conditions, and suggests that the proportion of FUO diagnosed as NIID has been increasing in recent decades. The presence of FUO that remain undiagnosed despite extensive investigations suggests the need for further research in this field. Of note, the prevalence of undiagnosed FUO is higher exactly where the most advanced diagnostics are available, suggesting the existence of diseases and conditions that are still elusive.

Strategies for optimizing the diagnostic approach for FUO should consider the main prevalent causes of fever in different areas, the local epidemiology, and the resources available. For these reasons, a global standardized diagnostic approach to FUO is not suitable. On the contrary, a standardization of FUO definition criteria is advisable. In particular, the adoption of a generally agreed minimal diagnostic work-up to be performed before qualifying a fever as FUO, would increase the generalisability and comparability of results of further studies.

In conclusion, despite the considerable advances in medical diagnostics and therapeutics, FUO still represent an intriguing challenge for clinicians, and further studies on this issue will continue to be advisable.

\section{Abbreviations}

CMV: Citomegalovirus; FUO: Fever of Unknown Origin; HIV/AIDS: Human Immunodeficency Virus / Acquired Immunodeficency Syndrome; ID: Infectious Diseases; NIII: Non-infectious inflammatory diseases: PRISMA: Transparent Reporting of Systematic Reviews and Meta-Analyses

\section{Acknowledgments}

No acknowledgments.

\section{Authors' contributions}

FMF and RP drafted the manuscript, performed data extraction and interpretation, contributed to study design; SDC performed data analysis and contributed to data interpretation; SN, GBG and GB designed the study, revised the manuscript for important intellectual content. All authors seen and approved the final version of the manuscript.

\section{Funding}

No dedicated funding has been used for this paper.

\section{Availability of data and materials}

All relevant data supporting the findings is contained within the manuscript. Database used for statistical calculations is available on request.

\section{Ethics approval and consent to participate}

no ethics approval is required in this particular case since it is a systematic review presenting collective data from other prospective/retrospective observational study; all procedures described followed the normal good standard of care, and have not been used experimental/innovative treatments and/or approaches; data from patients have been presented only in a general manner, and no patient can be recognized by third parties.

\section{Consent for publication}

Not applicable.

\section{Competing interests}

All authors declare that they have no competing interests. One of the author (FMF) is Associated Editor for BMC Infectious Diseases.

\section{Author details}

${ }^{1}$ Infectious Diseases Unit 1, S. Maria Annunziata Hospital, Central Tuscany Health Unit, Via dell'Antella 54, 50012 Bagno a Ripoli, Fl, Italy. ${ }^{2}$ Epidemiology and Pre-clinical Research Department, National Institute for Infectious Diseases "L. Spallanzani", Rome, Italy. Infectious Diseases and Viral Hepatitis, Department of Mental and Physical Health and Preventive Medicine, University of Campania "Luigi Vanvitelli", Naples, Italy. ${ }^{4}$ Infectious Diseases, Azienda Ospedaliera, University of Campania "Luigi Vanvitelli", Naples, Italy. ${ }^{5}$ Infectious Diseases, Department of Mental and Physical Health and Preventive Medicine, University of Campania "Luigi Vanvitelli", Naples, Italy. ${ }^{6}$ Department of Molecular Medicine, Infectious Diseases, University of Padua, Padua, Italy.

Received: 14 February 2019 Accepted: 12 July 2019

Published online: 22 July 2019

\section{References}

1. Petersdorf RG, Beeson P. Fever of unexplained origin: report on 100 cases. Medicine (Baltimore). 1961;40:1-30.

2. Durak DT, Street AC. Fever of unknown origin - re-examined and refined. Curr Clin Top Infect Dis. 1991:11:35-51.

3. Bleeker-Rovers CP, Vos FJ, de Kleijn EM, et al. A prospective multicentre study on fever of unknown origin: the yield of a structured diagnostic protocol. Medicine (Baltimore). 2007;86(1):26-38.

4. de Kleijn EM, Vandenbroucke JP, van der Meer JW. Fever of unknown origin (FUO). I. a prospective multicentre study of 167 patients with FUO, using fixed epidemiologic entry criteria. The Netherlands FUO study group. Medicine (Baltimore). 1997;76:392-400.

5. Knockaert DC, Vanderschueren S, Blockmans D. Fever of unknown origin in adults: 40 years on. J Intern Med. 2003;253:263-75.

6. Petersdorf RG. Fever of unknown origin. An old friend revisited. Arch Intern Med. 1992:152:21-2.

7. Mourad O, Palda V, Detsky AS. A comprehensive evidence-based approach to fever of unknown origin. Arch Intern Med. 2003:163:545-51.

8. Gaeta GB, Fusco FM, Nardiello S. Fever of unknown origin: a systematic review of the literature for 1995-2004. Nucl Med Commun. 2006:27(3):205-11.

9. Ottawa Hospital Research Institute and University of Oxford. PRISMA. Transparent reporting of systematic reviews and meta-analyses. Available from: http://www.prisma-statement.org/. Accessed 15 Mar 2018.

10. Murad MH, Sultan S, Haffar S, Bazerbachi F. Methodological quality and synthesis of case series and case reports. BMJ Evid Based Med. 2018;23(2):60-3.

11. Yu KK, Chen SS, Ling QX, et al. Fever of unknown origin: report of 107 cases in a university hospital. Int J Clin Exp Med. 2014;7(12):5862-6.

12. Mir T, Nabi Dhobi G, Nabi Koul A, Saleh T. Clinical profile of classical fever of unknown origin (FUO). Caspian J Intern Med. 2014;5(1):35-9.

13. Naito T, Mizooka M, Mitsumoto F, et al. Diagnostic workup for fever of unknown origin: a multicentre collaborative retrospective study. BMJ Open. 2013;3(12):e003971.

14. Robine A, Hot A, Maucort-Boulch D, Iwaz J, Broussolle C, Sève P. Fever of unknown origin in the 2000s: evaluation of 103 cases over eleven years. Presse Med. 2014;43(9):e233-40.

15. Vanderschueren $S$, Eyckmans T, De Munter P, Knockaert D. Mortality in patients presenting with fever of unknown origin. Acta Clin Belg. 2014;69(1):12-6.

16. Alavi SM, Nadimi M, Zamani GA. Changing pattern of infectious etiology of fever of unknown origin (FUO) in adult patients in Ahvaz, Iran. Caspian J Intern Med. 2013:4(3):722-6.

17. Mahmood K, Akhtar T, Naeem M, Talib A, Haider I. Siraj-us-Salikeen. Fever of unknown origin at a teritiary care teaching hospital in Pakistan. Southeast Asian J Trop Med Public Health. 2013;44(3):503-11. 
18. Shi $X C$, Liu $X Q$, Zhou BT, et al. Major causes of fever of unknown origin at Peking union medical college hospital in the past 26 years. Chin Med J. 2013;126(5):808-12.

19. Mete $B$, Vanli $E$, Yemisen $M$, et al. The role of invasive and non-invasive procedures in diagnosing fever of unknown origin. Int J Med Sci. 2012;9(8):682-9.

20. Pedersen TI, Roed C, Knudsen LS, Loft A, Skinhoj P, Nielsen SD. Fever of unknown origin: a retrospective study of 52 cases with evaluation of the diagnostic utility of FDG-PET/CT. Scand J Infect Dis. 2012;44(1):18-23.

21. Ali-Eldin FA, Abdelhakam SM, Ali-Eldin ZA. Clinical spectrum of fever of unknown origin among adult Egyptian patients admitted to Ain Shams University hospitals: a hospital based study. J Egypt Soc Parasitol. 2011; 41(2):379-86.

22. Bandyopadhyay D, Bandyopadhyay R, Paul R, Roy D. Etiological study of fever of unknown origin in patients admitted to medicine ward of a teaching hospital of eastern India. J Global Infect Dis. 2011:3(4):329-33.

23. Adil Khalil RM, Al-Kazzaz RH, Ghanim H, Al-Layla DJ. Fever of unknown origin: a prospective study in northern Iraq. Ann Coll Med Mosul. 2010;36:26-35.

24. Hu Y, Lu H, Zhang Y, et al. Fever of unknown origin: revisit of 142 cases in a tertiary Chinese hospital. Biosci Trends. 2008;2(1):44-6.

25. Kucukardali Y, Oncul O, Cavuslu S, et al. The spectrum of diseases causing fever of unknown origin in Turkey: a multicenter study. Int J Infect Dis. 2008; 12(1):71-9.

26. Colpan A, Onguru P, Erbay A, et al. Fever of unknown origin: analysis of 71 consecutive cases. Am J Med Sci. 2007;334(2):92-6.

27. Chin C, Chen YS, Lee SS, et al. Fever of unknown origin in Taiwan. Infection. 2006;34(2):75-80.

28. The World Bank. Country Classification. Available from: https://datahelpdesk. worldbank.org/knowledgebase/topics/19280-country-classification. Accessed 15 Mar 2018.

29. Clarke M. Interpreting the results of systematic reviews. Semin Hematol. 2008;45(3):176-80.

30. Austin PC. Estimating multilevel logistic regression models when the number of clusters is low: a comparison of different statistical software procedures. Int J Biostat. 2010;6(1):16.

\section{Publisher's Note}

Springer Nature remains neutral with regard to jurisdictional claims in published maps and institutional affiliations.

Ready to submit your research? Choose BMC and benefit from:

- fast, convenient online submission

- thorough peer review by experienced researchers in your field

- rapid publication on acceptance

- support for research data, including large and complex data types

- gold Open Access which fosters wider collaboration and increased citations

- maximum visibility for your research: over $100 \mathrm{M}$ website views per year

At $\mathrm{BMC}$, research is always in progress.

Learn more biomedcentral.com/submissions 